Article

\title{
The Maize WRKY Transcription Factor ZmWRKY40 Confers Drought Resistance in Transgenic Arabidopsis
}

\author{
Chang-Tao Wang ${ }^{1,+}$, Jing-Na Ru ${ }^{2,+}$, Yong-Wei Liu ${ }^{3}$, Jun-Feng Yang ${ }^{4}$, Meng $\mathrm{Li}^{1}{ }^{1}$, \\ Zhao-Shi $\mathrm{Xu}^{2, *}$ (i) and Jin-Dong Fu ${ }^{2, *}$ \\ 1 Beijing Advanced Innovation Center for Food Nutrition and Human Health/Beijing Key Lab of Plant \\ Resource Research and Development, Beijing Technology and Business University, Beijing 100048, China; \\ wangct@th.btbu.edu.cn (C.-T.W.); limeng@th.btbu.edu.cn (M.L.) \\ 2 Institute of Crop Science, Chinese Academy of Agricultural Sciences (CAAS)/National Key Facility for Crop \\ Gene Resources and Genetic Improvement, Key Laboratory of Biology and Genetic Improvement of \\ Triticeae Crops, Ministry of Agriculture, Beijing 100081, China; rujingna1993@163.com \\ 3 Institute of Genetics and Physiology, Hebei Academy of Agriculture and Forestry Sciences/Plant Genetic \\ Engineering Center of Hebei Province, Shijiazhuang 050051, China; liuywmail@126.com \\ 4 Hebei Wangfeng Seed Industry Co., Ltd., Xingtai 054900, China; Yangjunfenghb@163.com \\ * Correspondence: xuzhaoshi@caas.cn (Z.-S.X.); fujindong@caas.cn (J.-D.F.) \\ + These authors contributed equally to this work.
}

Received: 13 July 2018; Accepted: 27 August 2018; Published: 30 August 2018

\begin{abstract}
Abiotic stresses restrict the growth and yield of crops. Plants have developed a number of regulatory mechanisms to respond to these stresses. WRKY transcription factors (TFs) are plant-specific transcription factors that play essential roles in multiple plant processes, including abiotic stress response. At present, little information regarding drought-related WRKY genes in maize is available. In this study, we identified a WRKY transcription factor gene from maize, named ZmWRKY40. ZmWRKY40 is a member of WRKY group II, localized in the nucleus of mesophyll protoplasts. Several stress-related transcriptional regulatory elements existed in the promoter region of ZmWRKY40. ZmWRKY40 was induced by drought, high salinity, high temperature, and abscisic acid (ABA). ZmWRKY40 could rapidly respond to drought with peak levels (more than 10-fold) at $1 \mathrm{~h}$ after treatment. Overexpression of ZmWRKY40 improved drought tolerance in transgenic Arabidopsis by regulating stress-related genes, and the reactive oxygen species (ROS) content in transgenic lines was reduced by enhancing the activities of peroxide dismutase (POD) and catalase (CAT) under drought stress. According to the results, the present study may provide a candidate gene involved in the drought stress response and a theoretical basis to understand the mechanisms of ZmWRKY40 in response to abiotic stresses in maize.
\end{abstract}

Keywords: WRKY; abiotic stress; regulatory mechanism; drought tolerance; maize

\section{Introduction}

Environmental stresses seriously affect plant growth and crop productivity. Meanwhile, traditional crop breeding methods cannot meet the production demands of fine varieties with stress tolerance. Cloning stress-related genes and using genetic engineering techniques to create new crop varieties with higher stress tolerance has become a comparatively effective method. Based on the evidence from previous research, transcription factors (TFs) may be promising potential stress-tolerant candidates [1-6]. 
As one of the largest TFs families in plants, WRKYs are characterized by their conservative WRKY domains that can specifically recognize the W-box element in the promoter of its target genes, and play an important role in gene transcription and regulation [7]. Depending on their structural features, the WRKYs can be divided into three basic groups: group I (contains two WRKY domains), group II and III (contain only one WRKY domain) [7]. The zinc finger motif in the WRKY domain (C-X4-5-C-X22-23-H-X1-H or C-X7-C-X23-H-Xe-C, respectively) is different between groups II and III [8].

As the first WRKY gene, SPF1, was identified in sweet potato [9], many WRKY TFs were identified in different species, including Arabidopsis [10], rice [11], soybean [12], and barley [13]. Currently, growing evidence has suggested that WRKY TFs play a central regulatory role in plant response to abiotic stress [14,15]. For instance, the overexpression of Arabidopsis WRKY genes AtWRKY25, AtWRKY26, and AtWRKY39 enhances heat tolerance, although the expression of AtWRKY25 and AtWRKY26 is inhibited by high-temperature stress [16,17]. In addition, the pepper CaWRKY40 and soybean GmWRKY13/21/54 genes confer tolerance to different abiotic stresses in transgenic plants $[18,19]$. Overexpressing the wheat TaWRKY33 enhanced the drought and heat tolerance of transgenic Arabidopsis [20]. WRKYs are involved in various hormone signaling pathways in plants. For example, AtWRKY40 can recognize the $\mathrm{W}$-box regions of abscisic acid (ABA)-induced genes such as AtABF4, AtABI4, AtABI5, AtDREB1A, AtMYB2, and AtRAB18, and suppress their expression [21]. Exogenous ABA can induce the expression of the cucumber CsWRKY46 gene, and overexpression of CsWRKY46 can improve the cold resistance in transgenic plants by regulating related genes in the ABA signaling pathway [22]. These findings confirm that WRKY TFs function as regulators in response to hormones or abiotic stresses.

Because of the wide ecological potential and excellent characteristics of maize (Zea mays L.), it is widely cultivated in the temperate zone and in the tropical belt. At present, the output of maize is badly affected by decreased cultivated areas and the ever-worsening environment, especially water scarcity. Even though numerous WRKY genes participate in plant abiotic stress responses, little information is available on the mechanisms of WRKYs in maize. One-hundred and nineteen WRKY genes from the maize B73 genome have been identified, which has made it possible to identify new abiotic stress-related WRKY genes in maize [23]. In this study, the de novo transcriptome sequencing of maize (SRP144573) under drought treatment was performed to investigate potential WRKY genes related to maize drought tolerance. We identified a drought-responsive WRKY gene ZmWRKY40 (GRMZM2G120320), a member of WRKY group II. Overexpression of ZmWRKY40 promoted root growth and reduced the water loss rates in transgenic Arabidopsis under drought stress. This study may provide a foundation to understand the function of WRKY genes in maize drought response.

\section{Results}

\subsection{De Novo Transcriptome Sequencing Analysis}

To find maize stress-responsive genes under drought stress, three-leaf seedlings were dehydrated on filter paper for $4 \mathrm{~h}$, and then were collected for transcriptome sequencing analysis. The results showed that the transcription levels of many genes have been changed after drought treatment (Supplementary Figure S1A). Gene ontology (GO) analyses were used to classify the differentially expressed genes (DEGs) into functional groups, and the DEGs were analyzed against the KEGG database to further understand which pathways the DEGs may be involved in (Supplementary Figure S1B,C). After selecting from the DEGs (the differentially expressed WRKYs are listed in Supplementary Table S2), we chose the gene ZmWRKY40 (GRMZM2G120320) for the further study.

\subsection{Phylogenetic Analysis of ZmWRKY40}

The complete encoding sequence of ZmWRKY40 was $1191 \mathrm{bp}$, encoding 396 amino acids. The ZmWRKY40 protein contained a conserved WRKYGQK domain, a coiled-coil domain (amino 
acids 102 to 142) at the N-terminus, and a zinc finger motif (C-X5-C-X23-H-X1-H) (Figure 1A). BLASTp online tool was used to search for the homologous amino acid sequences of ZmWRKY40 in wheat and Arabidopsis.
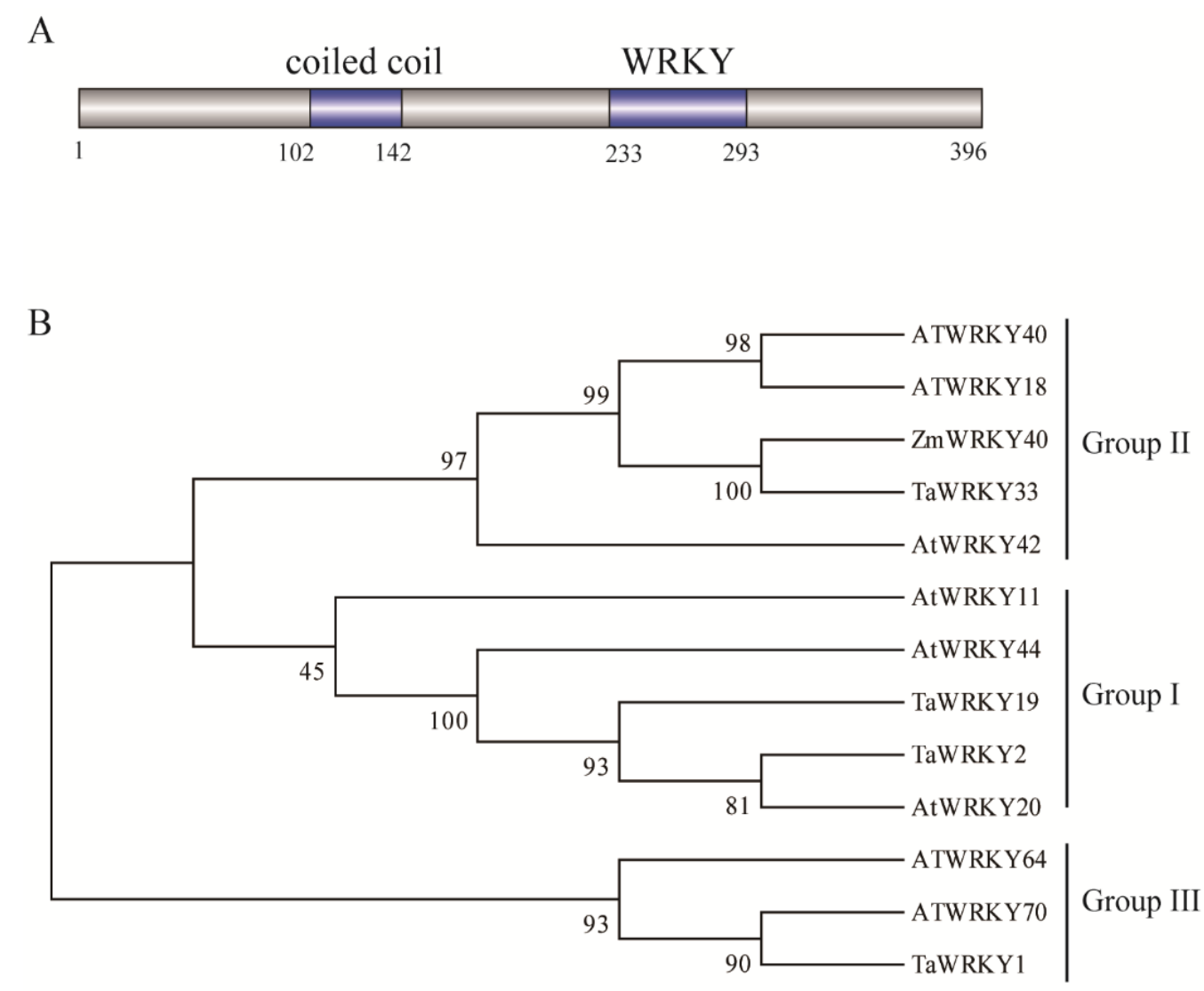

Figure 1. Domain organization and phylogenetic analysis of ZmWRKY40. (A) Domain organization of ZmWRKY40. (B) Phylogenetic relationship of ZmWRKY40 and other orthologs in different species. Thirteen WRKY proteins from three species were divided into three groups. The phylogenetic tree was produced using the neighbor-joining method with 1000 bootstraps by the MEGA5.0 program.

According to the criteria of classification of Ulker et al., (2004) [8] and multiple amino acid sequence alignment, five proteins (TaWRKY2, -19; AtWRKY11, -44, and -20) belonged to group I and each contained two WRKY domains; three proteins (AtWRKY64, -70 and TaWRKY1) belonged to group III, five proteins were belonged to group II, and ZmWRKY40 was classified as a member of group II (Figure 1B).

\subsection{ZmWRKY40 Protein Was Localized in the Nucleus}

To find out the sub-cellular localization of ZmWRKY40 fusion protein, the ZmWRKY40-green fluorescent protein (GFP) recombinant was transformed into maize mesophyll protoplasts and the p16318hGFP vector was transformed as a control. As shown in Figure 2, the p16318hGFP protein was expressed in the whole cell, while the ZmWRKY40-GFP fusion protein was localized in the nucleus. 


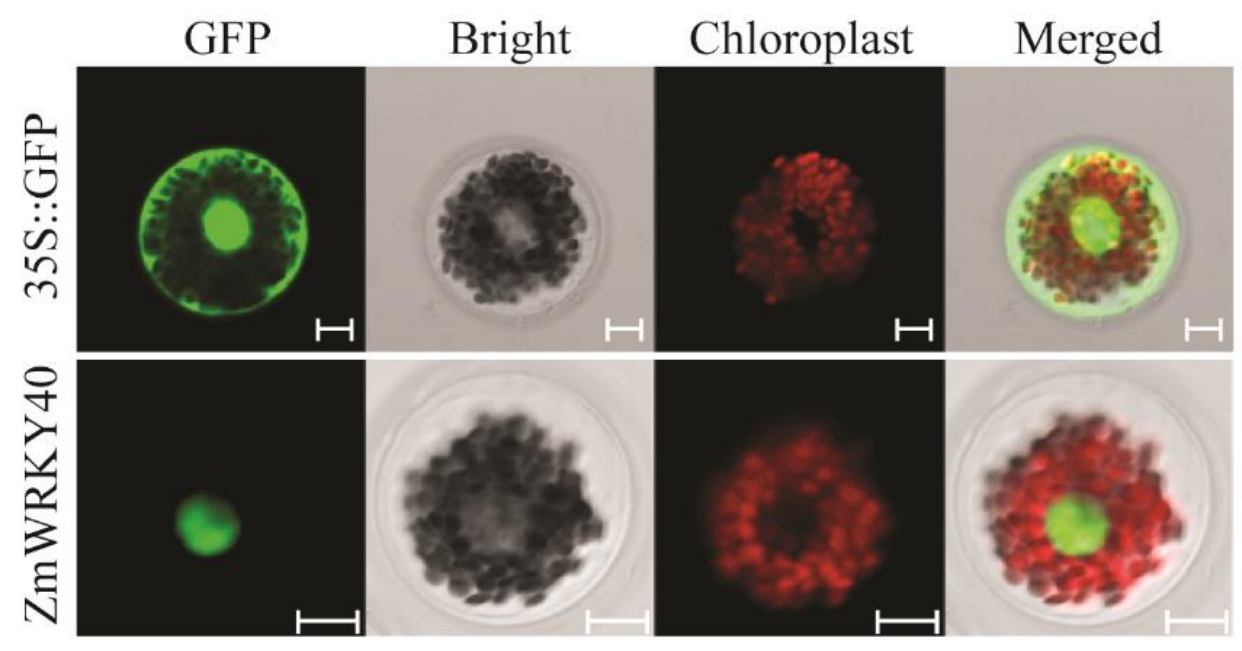

Figure 2. Subcellular localization of ZmWRKY40. ZmWRKY40-green fluorescent protein (GFP) recombinant and $\mathrm{p} 16318 \mathrm{hGFP}$ control vector were transiently expressed in maize protoplasts. Scale bars $=10 \mu \mathrm{m}$.

\subsection{ZmWRKY40 Was Involved in Multiple Abiotic Stresses}

Numerous cis-regulatory elements were identified by the online database PLACE (available online: http:/ / www.dna.affrc.go.jp/PLACE/) (Table 1). As shown in Table 1, the promoter region of ZmWRKY40 contained various abiotic stress-related elements, such as ABA-responsive element (ABRE), MYB, gibberellin (GA)-responsive element (GARE), and W-box, which suggested that ZmWRKY40 may function in abiotic stress response.

Table 1. Putative cis-elements in the ZmWRKY40 promoter.

\begin{tabular}{cccc}
\hline Elements & Number & Sequence & Function \\
\hline ABRE & 6 & ACGTG/ACGTSSSC/MACGYGB & ABA- and drought-responsive elements \\
\hline MYB & 2 & $\begin{array}{c}\text { WAACCA/YAACKG/CTAACCA/ } \\
\text { CNGTTR/AACGG/TAACAAA }\end{array}$ & ABA- and drought-responsive elements \\
\hline GARE & 2 & TAACAAR & GA-responsive element \\
ATC-motif & 1 & TGCTATCCG & Light-responsive element \\
AuxRe-core & 1 & GGTCCAT & Auxin-responsive element \\
W-Box & 1 & TTTGACY/TTGAC/CTGACY/TGACY & SA-responsive element \\
\hline $\begin{array}{c}\text { ABA-abscisic acid; } \\
\text { responsive element. }\end{array}$ & ABRE-ABA-responsive element; GA-gibberellin; SA-salicylic acid; GARE-GA- &
\end{tabular}

In this study, we investigated the response of ZmWRKY40 to various abiotic stresses by quantitative real-time PCR (qRT-PCR). The results showed that ZmWRKY40 was induced by drought, high-temperature, $\mathrm{NaCl}$, and $\mathrm{ABA}$ stresses, while it was not affected by low temperature (Figure 3). The expression of ZmWRKY 40 peaked (more than 10-fold) after $1 \mathrm{~h}$ of drought treatment. Under salt stress, the transcript of ZmWRKY40 peaked (8.87-fold) at $2 \mathrm{~h}$, and then declined rapidly to a level similar to the control. Under high-temperature and exogenous ABA treatments, the transcript levels of ZmWRKY40 were up-regulated and peaked at $2 \mathrm{~h}$ (3.08-fold) and $12 \mathrm{~h}$ (3.38-fold), respectively. 
A

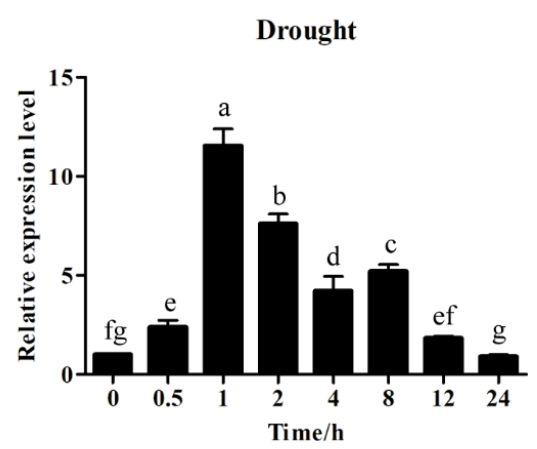

$\mathrm{C}$

High-temperature $\left(4^{\circ} \mathrm{C}\right)$

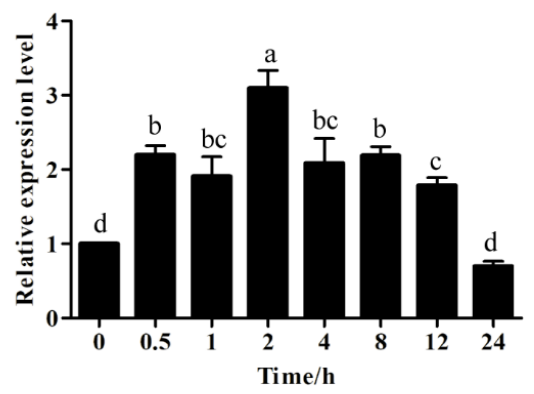

$\mathrm{E}$

$\mathrm{ABA}(100 \mu \mathrm{M})$

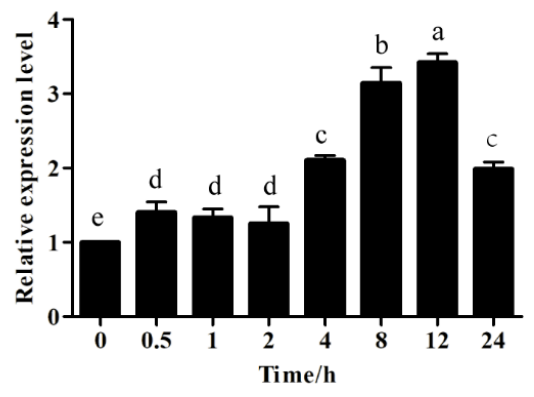

B

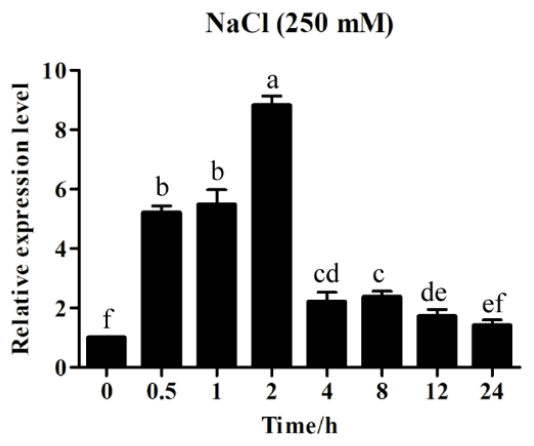

$\mathrm{D}$ Low-temperature $\left(4^{\circ} \mathrm{C}\right)$

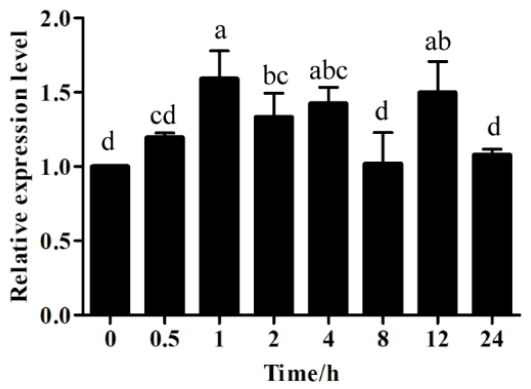

Figure 3. Expression patterns of $Z m W R K Y 40$ under drought (A), $\mathrm{NaCl}$ (B), high-temperature (C), low-temperature (D), and exogenous ABA (E). The vertical ordinates represent fold changes and the horizontal ordinates represent treatment times. Error bar represent standard deviations (SD). The data represent means $\pm S D$ of three biological replications. Different letters in bar graphs indicate significant differences at $p<0.05$. ABA-abscisic acid.

\subsection{ZmWRKY40 Enhanced Drought Tolerance in Transgenic Plants}

WT was used as the background to transfer the PBI121-ZmWRKY40. Three T3 transgenic Arabidopsis lines overexpressing ZmWRKY40 were selected to be analyzed. Under normal conditions, no differences were observed in seed germination rates between WT and transgenic plants (Figure 4). In the presence of $4 \%$ and $8 \%$ PEG6000, the germination rate of transgenic seeds was significantly higher than WT (Figure 4). Likewise, the transgenic lines and WT seedlings had little difference in total root length under normal conditions (Figure 5). When exposed to 10\% PEG6000, total root lengths of transgenic lines were longer than the WT seedlings after cultivating for seven days, although the growth of both transgenic and WT plants was repressed by PEG6000 (Figure 5). In the seedling stage, there was no significant difference between transgenic and WT plants (Figure 6). However, the transgenic lines were stronger than WT after drought treatment, the survival and water loss 
rates of transgenic lines and WT plants during drought treatment were measured, and the transgenic lines showed higher survival and lower water loss rates than those of WT plants (Figure 6). Other stress treatments including $\mathrm{NaCl}$ treatment in the seedling stage and stomatal apertures experiment under ABA treatment were also carried out, but the ZmWRKY40-overexpressing plants exhibited no significant difference under salt and ABA stresses.

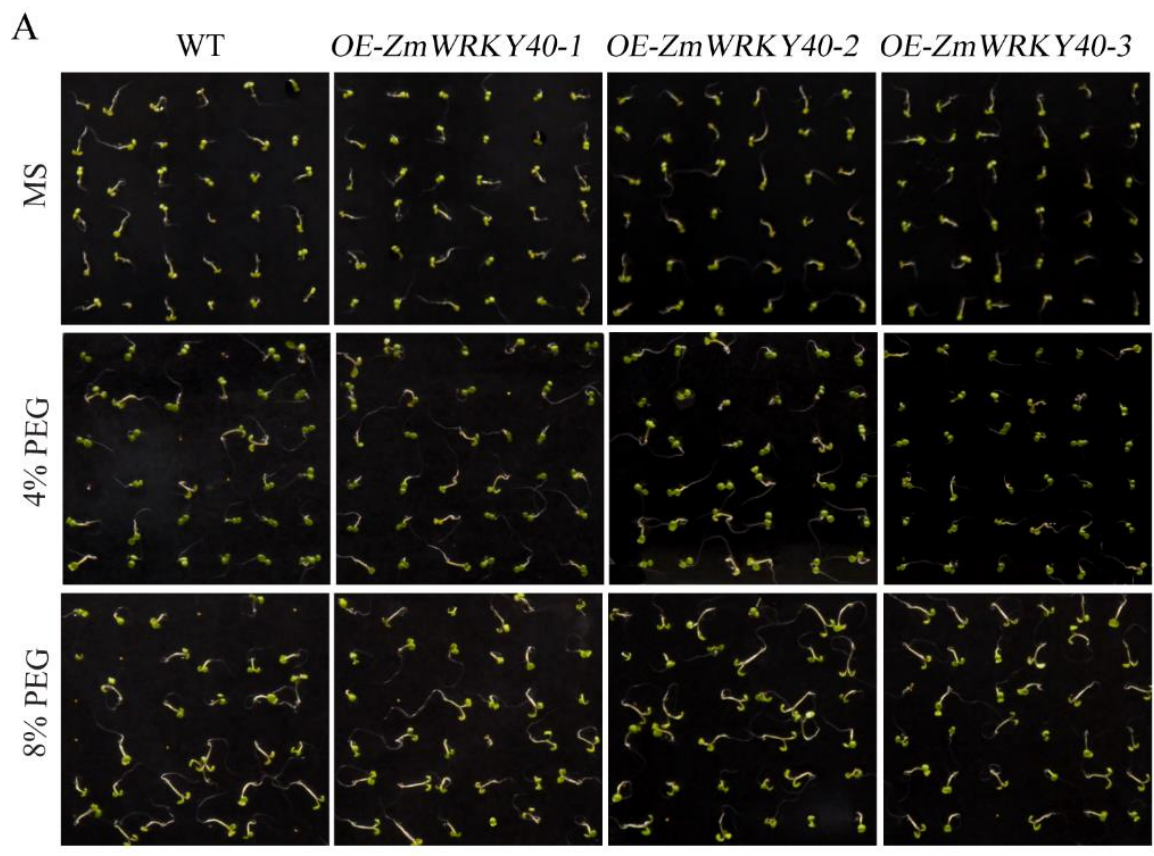

$\mathrm{B}$
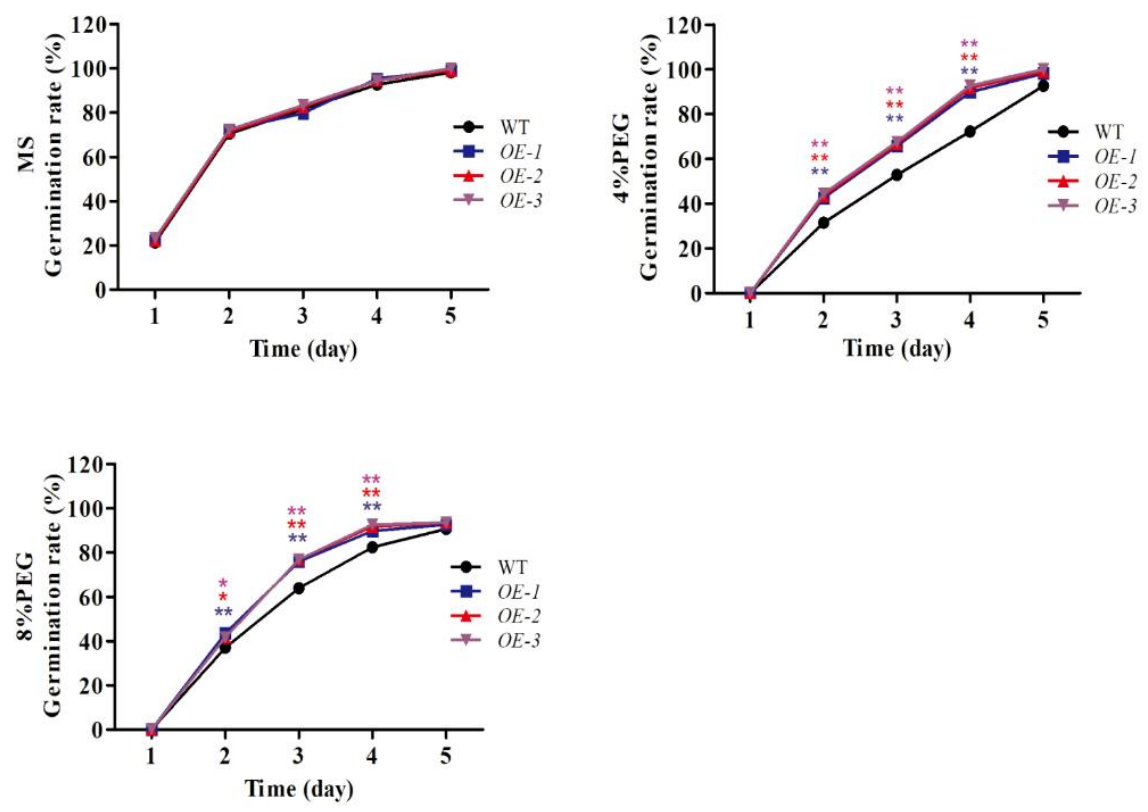

Figure 4. Germination of transgenic Arabidopsis lines under drought stress. Seeds were incubated at $4{ }^{\circ} \mathrm{C}$ for three days followed by $22{ }^{\circ} \mathrm{C}$ for germination. Seeds from three independent transgenic lines with ZmWRKY40 were grown on MS medium and MS added $4 \%$ or $8 \%$ PEG6000 (A). The germination rate of seeds grown on MS medium and MS medium with 4\% or 8\% PEG6000 (B). All the data represent the means \pm SDs of three independent biological replicates and asterisks ${ }^{* *}$ ) represent the significant differences at $p<0.01$ (Student's $t$-test). WT-wild-type. 
A
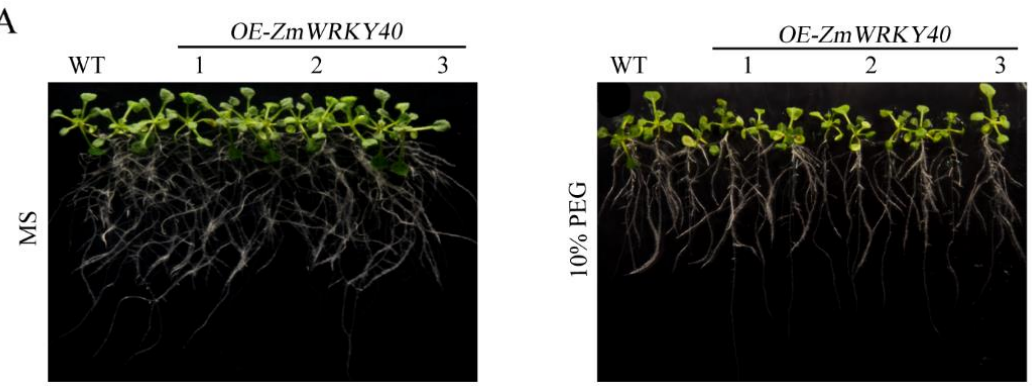

B

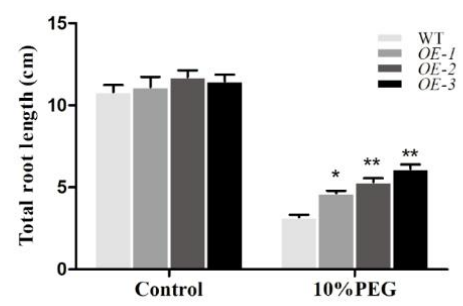

Figure 5. Total root lengths of transgenic Arabidopsis lines under drought stress. Five-day-old Arabidopsis seedlings were planted on MS medium with or without 10\% PEG6000 for 7 days (A). The total root lengths were measured (B). Data are means \pm SD of three independent experiments, and asterisks $\left({ }^{*}\right.$ or $\left.^{* *}\right)$ represent the significant differences at $p<0.05$ or $p<0.01$, respectively (Student's $t$-test).

A

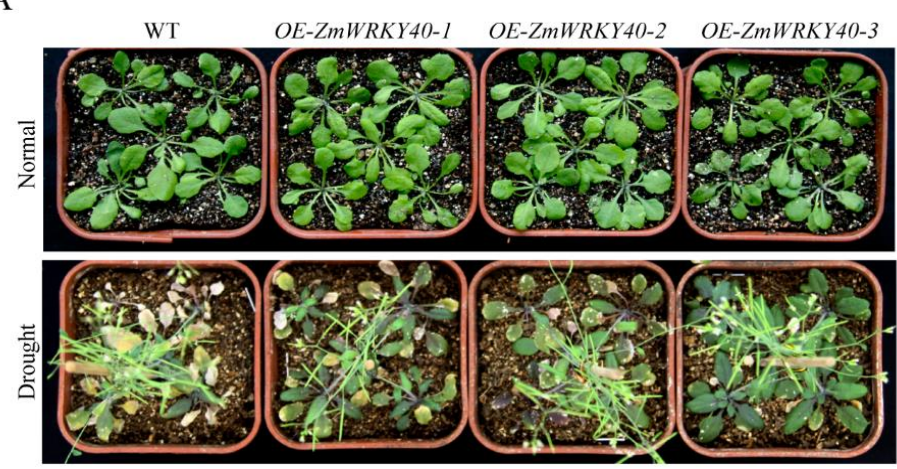

B

C
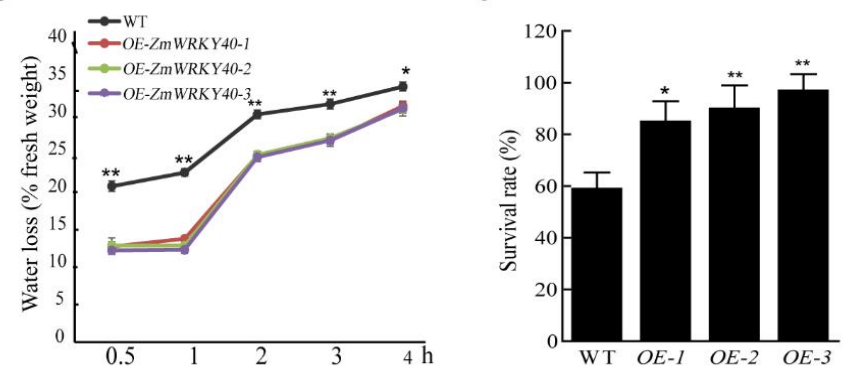

Figure 6. Phenotype analysis and the water loss and survival rates of transgenic Arabidopsis and WT under drought treatment. Phenotype analysis of WT and the transgenic Arabidopsis under drought treatment (A). The water loss rate of WT and transgenic plants under drought condition (B). The survival rate of WT and transgenic plants under drought condition was monitored seven days after rewatering $(\mathbf{C})$. Data are means \pm SD of three independent experiments, and asterisks $\left({ }^{*}\right.$ or ${ }^{* *}$ ) represent the significant differences at $p<0.05$ or $p<0.01$, respectively (Student's $t$-test). 


\subsection{ZmWRKY40 Changes the Expression of Stress-Responsive Gene}

To further research the possible molecular mechanisms of ZmWRKY40 in stress responses, the relative expression levels of stress-responsive genes were determined in transgenic and WT plants under normal conditions. The results showed that stress-responsive genes $S T Z, D R E B 2 B$, and $R D 29 A$ had a more than two-fold increase in transgenic Arabidopsis relative to WT plants (Figure 7). These results suggested that $Z m W R K Y 40$ may play a role in drought stress response by regulating stress-related genes.

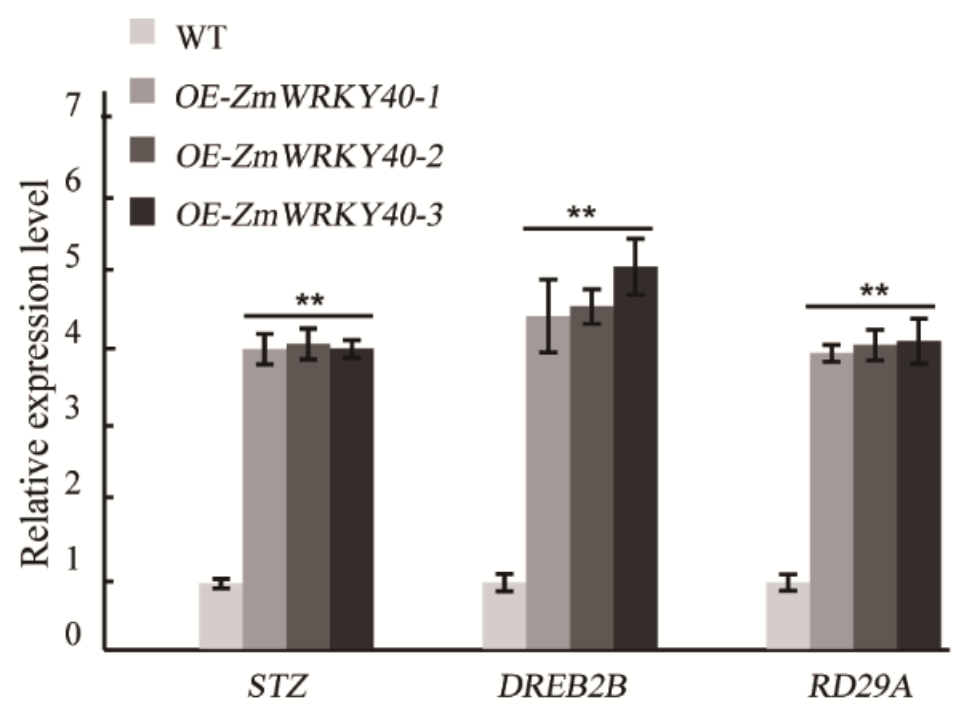

Figure 7. Expression levels of stress-responsive genes in WT and transgenic Arabidopsis under normal conditions. The vertical coordinates are fold changes and the horizontal ordinates are gene names. Values are means \pm SDs of three replicates, and asterisks $\left({ }^{*}\right.$ or $\left.{ }^{* *}\right)$ represent the significant differences at $p<0.05$ or $p<0.01$, respectively (Student's $t$-test).

\subsection{ZmWRKY40 Changes the Reactive Oxygen Species (ROS) Content and Enzyme Activity}

To better understand the function of ZmWRKY40 under drought treatment, we assessed the activities of POD and CAT and the ROS content in ZmWRKY40 transgenic and WT plants at $0 \mathrm{~h}, 6 \mathrm{~h}$, and $24 \mathrm{~h}$ after drought treatment (Figure 8). The ROS content of WT remained at approximately $0.37 \mathrm{U}$ for all of the time points, and the content in transgenic lines had a higher accumulation compared with $\mathrm{WT}$, reaching the maximum at $12 \mathrm{~h}$ after drought treatment (Figure $8 \mathrm{~A}$ ). The activities of two antioxidant enzymes, POD and CAT, in transgenic lines were significantly higher than WT plants (Figure 8B,C). As shown in Figure 7B, increases of POD activity were observed in both WT and transgenic lines, but the POD activity in transgenic lines remained higher than in WT plants at all time points, reaching the maximum at $24 \mathrm{~h}$ after drought treatment. The activity of CAT was almost unchanged in WT plants under drought treatment, while in transgenic lines, the activity of CAT had a significantly higher level than WT plants (Figure 8C). Overexpression of ZmWRKY40 reduced the ROS content and enhanced the activities of POD and CAT in transgenic lines under drought stress. 
A

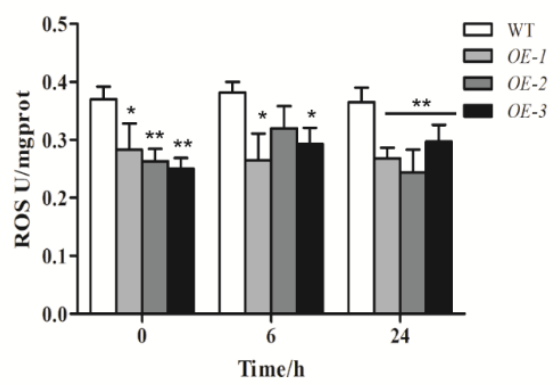

$\mathrm{C}$

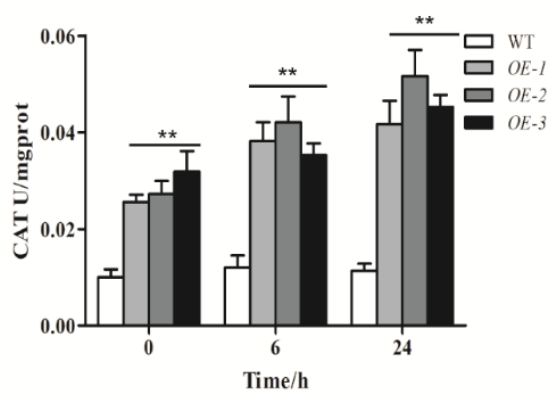

B

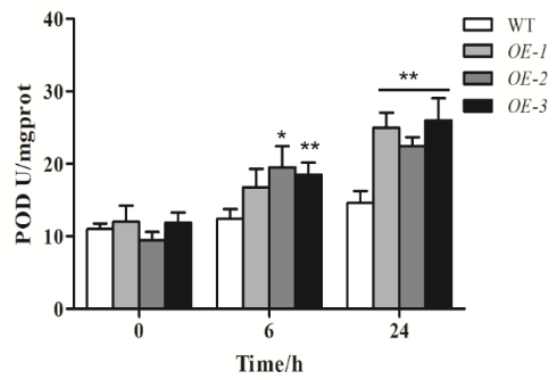

Figure 8. The measurements of physiological-biochemical parameters under normal and drought conditions. The reactive oxygen species (ROS) content (A) and the activities of peroxide dismutase (POD) (B) and catalase (CAT) (C) in WT and transgenic lines were measured. Values are means \pm SDs of three replicates, and asterisks $\left({ }^{*}\right.$ or ${ }^{* *}$ ) represent the significant differences at $p<0.05$ or $p<0.01$, respectively (Student's $t$-test).

\section{Discussion}

As one of the most serious environmental stresses, drought has a severe effect on the quality and yield of crops. Hence, many studies on drought-related genes have been carried out $[1,24,25]$. WRKY transcription factors are a class of plant-specific transcription factors that have been mostly reported in the regulation of plant defense responses against biotic stress [26-28]. For example, 49 Arabidopsis WRKY genes were induced by pathogens or salicylic acid [29]. In addition to playing an important role in biotic stress responses, WRKYs also regulate plant responses to abiotic stresses, such as high salt, drought, and high and low temperatures [8,30-33]. As the first WRKY protein was isolated from sweet potato [9], many WRKYs have been identified, and numerous WRKYs conferring abiotic stress responses have been studied in many plants. For example, AtWRKY30 could enhance abiotic stress tolerance during early growth stages in Arabidopsis by binding to W-boxes in promoters of many stress-regulated genes [34]. Overexpressing AtWRKY47 increased drought resistance in Arabidopsis, and AtWRKY57 enhanced drought tolerance in both transgenic Arabidopsis and rice plants $[35,36]$. OsWRKY30 is activated by MAP kinases to confer drought tolerance in rice, and overexpressing OsWRKY45 improved salt and drought stress tolerance of transgenic Arabidopsis [37]. In wheat, 15 wheat cDNAs were isolated, and 8 genes were responsive to low-temperature, high-temperature, $\mathrm{NaCl}$ or PEG treatment [38]. Ten WRKY genes were identified from the genome of wheat, of which TaWRKY10 enhanced drought and salt stress tolerance in tobacco by regulating the osmotic balance, ROS scavenging, and transcription of stress-related genes [32]. Moreover, GmWRKY27 interacted with GmMYB174 to improve salt and drought tolerance in transgenic soybean hairy roots by suppressing the expression of GmNAC29 [39]. These results all suggest that WRKYs play important roles in responding to abiotic stresses. 
Maize is one of the most important economic crops, but very few WRKY proteins have been studied in maize, especially regarding their roles in abiotic stress [40]. Since the whole-genome sequencing of maize was completed in 2009, more bioinformatics studies have been conducted to identify the gene families of maize [23,41,42]. For example, a total of 136 WRKYs coded by 119 genes were identified from the maize genome and were numbered [23]. Accordingly, we identified a WRKY gene, $Z m W R K Y 40$, selected from the drought-treated maize de novo transcriptome data in this study. Similar to other WRKY members, ZmWRKY40 contained one conserved WRKY domain (Figure 1), meaning that it may retain a similar function to other WRKY proteins [23]. To our knowledge, few WRKY genes have been studied in maize. ZmWRKY17 negatively regulated salt stress tolerance and decreased ABA sensitivity through regulating the expression of some ABA- and stress-responsive genes [43]. ZmWRKY33 was induced by high-salt, dehydration, cold, and ABA treatments, and it enhanced salt stress tolerance in transgenic Arabidopsis [40]. Moreover, ZmWRKY58 improved tolerance to drought and salt stresses in transgenic rice [44]. These results all suggest that maize WRKYs may play an important role in responding to abiotic stresses.

In our study, ZmWRKY40 was mainly induced by drought, high-temperature, salt, and exogenous ABA treatments (Figure 3), which may be related to the cis-acting elements of its promoter region (Table 1). For instance, the ABRE and MYB recognition sites in the ZmWRKY40 promoter region may be responsible for various abiotic stresses and may be involved in ABA signaling. Previous studies have revealed that overexpression of WRKYs in plants can enhance tolerance to drought, salt, cold, and heat stress $[14,16,19,33]$, or can only improve plant tolerance to a single abiotic stress, such as drought [35], salt [40], or heat stress [17]. ZmWRKY40 improved tolerance to drought in transgenic Arabidopsis (Figures 4-6), and we also observed the phenotype of ZmWRKY40-overexpressing plants in the seedling stage under $\mathrm{NaCl}$ treatment, but there was no significant difference. ABA is an important phytohormone, and plays a critical role in regulating plant response to abiotic stresses. Previous studies have demonstrated that there existed ABA-dependent and ABA-independent pathways in drought response $[45,46]$. Under drought conditions, plants accumulated a high level of ABA, which induced stomatal closure to reduce water loss [47]. The stomatal apertures experiment under ABA treatment was also carried out in our study, but there was no significant difference between ZmWRKY40-overexpressing plants and wild-type (WT), which revealed that ZmWRKY40 was involved in drought stress through ABA-independent signal pathway. ROS are important signaling molecules in the regulation of many of biological processes, and many studies have revealed that the capacity of ROS scavenging was associated with plant tolerance to abiotic stresses [48-51]. Overexpression of ZmWRKY40 reduced ROS content and enhanced the activities of POD and CAT under drought treatment (Figure 8), which briefly suggested that ZmWRKY 40 might improve the tolerance to drought by regulating ROS scavenging. Furthermore, overexpression of ZmWRKY40 activated the expression of stress-responsive genes STZ, DREB2B, and RD29A (Figure 7). STZ, as a transcriptional repressor, enhanced the abiotic stress resistance when overexpressed in transgenic Arabidopsis or rice [52]. $D R E B$ is known to regulate the expression of many stress-inducible genes in the ABA-independent pathways. DREB2B was induced by drought, and overexpressing DREB2B resulted in significant drought tolerance in transgenic Arabidopsis plants [53]. RD29A contains two major cis-acting elements, the ABRE and the cis-acting DRE, both of which were involved in stress-inducible gene expression [54]. Collectively, these findings show that overexpression of ZmWRKY40 could improve drought tolerance in transgenic plants possibly by regulating ROS scavenging and enhancing the expression levels of stress-responsive genes. Though ZmWRKY40 could improve the transgenic Arabidopsis resistance to drought, its function in maize still needs to be investigated. Despite this, the function of ZmWRKY40 in transgenic Arabidopsis suggests the future direction of research in maize or other crops. 


\section{Materials and Methods}

\subsection{De Novo Transcriptome Sequencing}

Three-leaf stage untreated maize seedlings and seedlings dehydrated on filter paper for four hours were collected for RNA-seq analysis. The detailed process of RNA-seq was exhibited as previously described [20]. The transcriptome data are available in NCBI under accession number SRP144573.

\subsection{Stress Treatments and Sample Collection}

Seeds of maize (X178) used in this study were provided by Dr Zhuan-Fang Hao (Institute of Crop Science, Chinese Academy of Agricultural Sciences, Beijing, China). Wild-type (WT) Arabidopsis (Columbia-0) was kept by our laboratory. We planted maize seeds in an incubator before transferring them to pots of $10 \mathrm{~cm}$ diameter, with 10 seedlings per pot. The soil contained vermiculite and nutrition soil in a ratio of $1: 1(v / v)$. The seedlings were grown in a culture room with $60-70 \%$ relative humidity, $25 \pm 2{ }^{\circ} \mathrm{C}$, and a photoperiod of $16 \mathrm{~h}$ light $/ 8 \mathrm{~h}$ dark at a light intensity of around $100 \mu \mathrm{M} \cdot \mathrm{m}^{-2} \mathrm{~s}^{-2} \mathrm{until}$ the three-leaf stage [55]. For the heat and cold stress treatments, the seedlings were exposed to $45^{\circ} \mathrm{C}$ and $4{ }^{\circ} \mathrm{C}$, respectively. For the exogenous $\mathrm{ABA}$ and $\mathrm{NaCl}$ treatments, the roots of maize seedlings were soaked in $100 \mu \mathrm{M} \mathrm{ABA}$ and $250 \mathrm{mM} \mathrm{NaCl}$ solutions, respectively [40]. For the drought stress treatment, the maize seedlings were placed on filter paper in the culture room [41]. Seedling samples were collected at $0,0.5,1,2,4,8,12$, and $24 \mathrm{~h}$ after different treatments. The un-treated transgenic and WT Arabidopsis were collected to analyze the expression of stress-related genes. The collected samples were dropped into liquid nitrogen for $15 \mathrm{~min}$ and then stored at $-80{ }^{\circ} \mathrm{C}$.

\subsection{Reverse Transcription PCR (RT-PCR) and Quantitative Real-Time PCR (qRT-PCR)}

The total RNAs were extracted from maize tissue with an RNAprep pure Plant Kit (TIANGEN, Beijing, China). The RT-PCR was conducted using an EasyScript One-Step gDNA Removal and cDNA Synthesis SuperMix kit (TransGen Biotech, Beijing, China). The qRT-PCR was performed with SuperReal PreMix Plus (TIANGEN, Beijing, China) on an ABI Prism 7500 system (Applied Biosystems, Foster City, CA, USA), and each qRT-PCR was repeated three times. The specific primers of ZmWRKY40 are listed in Supplementary Table S1. The data were analyzed according to the earlier description [56].

\subsection{Gene Isolation and Bioinformatics Analysis}

The full-length of ZmWRKY40 was amplified from maize cDNA. The primers of ZmWRKY40-F and ZmWRKY40-R were listed in Supplementary Table S1. The PCR products were cloned into the pEASY-T1 vectors (TransGen Biotech, Beijing, China) and sequenced. The protein functional domains of ZmWRKY40 were predicted by the online analysis tool SMART (available online: http:/ / smart. embl.de/). The amino acid sequence of ZmWRKY40 was used to search the other orthologs from online NCBI database (available online: https: / / www.ncbi.nlm.nih.gov/) using the BLASTP program. Thirteen WRKY proteins from three species were used for the phylogenetic analysis. The multiple sequence alignments were conducted using ClustalW [57], and the phylogenic tree analysis was performed by MEGA5.0 software with the neighbor-joining (NJ) method [58]. We set default values for all the parameters, and the confidence levels were estimated with bootstrap analyses of 1000 replicates. For further analysis of the transcriptional regulation mechanism of ZmWRKY40, cis-elements in the promoter region of ZmWRKY40 were predicted as reported by Zhao et al., 2016 [22].

\subsection{Subcellular Localization}

The expression vector p16318hGFP was used for an investigation of subcellular localization. The coding region of ZmWRKY40 was fused to p16318hGFP vector containing the CaMV35S promoter. The specific primers were listed in Supplementary Table S1. To confirm the location of ZmWRKY40 
fusion protein in cells, the ZmWRKY40-GFP recombinant was transformed into maize mesophyll protoplasts by the PEG-mediated method as described by He et al., 2016 [20]. Transfected protoplasts were incubated in darkness at $22{ }^{\circ} \mathrm{C}$ for more than $18 \mathrm{~h}$. The fluorescence signals were monitored by a confocal laser scanning microscopy (LSM700; CarlZeiss, Oberkochen, Germany).

\subsection{Generation of Transgenic Arabidopsis and Its Phenotype under Stress Treatment}

The full-length of ZmWRKY40 was constructed to the plant expression vector pBI121, and the recombinant was transformed to wild-type (WT) Arabidopsis (Columbia-0) using the Agrobacterium-mediated floral dip method. The specific primers are listed in Supplementary Table S1. The transformed seeds were selected on MS medium containing $50 \mathrm{mM}$ Kanamycin to obtain the positive plants. Three $\mathrm{T}_{3}$ generation overexpression lines (OE-ZmWRKY40-1, OE-ZmWRKY40-2, OE-ZmWRKY40-3) with higher expression levels of ZmWRKY40 were selected by qRT-PCR for further analysis. The method to clean Arabidopsis seeds was described by Feng et al., 2015 [1].

Germination assay and root growth assay were used to identify the phenotype under drought stress. For germination assay, seeds of WT and transgenic Arabidopsis lines were cultured in MS medium and MS added $4 \%(w / v)$ or $8 \%$ PEG6000 for a week. All the media were incubated at $4{ }^{\circ} \mathrm{C}$ for three days before moving to $22^{\circ} \mathrm{C}$ with a photoperiod of $16 \mathrm{~h}$ light $/ 8 \mathrm{~h}$ dark. Seeds were considered to be germinated when radicles emerged from the seed coats. For root growth assay, five-day-old seedlings were transferred to MS medium without or with 10\% PEG6000 for seven days, and total root lengths of Arabidopsis lines were measured [59]. All the experiments were repeated three times.

For the drought treatment, 10-day transgenic and WT plants were transferred to pots filled with a 1:1 mixture of rich soil and vermiculite, and the seedlings were grown at $22{ }^{\circ} \mathrm{C}$ with a light intensity of around $100 \mu \mathrm{M} \cdot \mathrm{m}^{-2} \mathrm{~s}^{-2}(16 \mathrm{~h}$ light $/ 8 \mathrm{~h}$ dark photoperiod) under $60 \%$ humidity conditions. After growing under normal conditions for three weeks, the drought treatment was imposed by withdrawing irrigation. After severe drought stress for two weeks, water was added for recovery; performance was photographed and the survival rate was monitored seven days after rewatering. Rosette leaves of WT and transgenic plants, which were grown under drought conditions for 7 days, were excised, weighed immediately, and incubated on a bench at room temperature with $60 \%$ humidity. Losses in fresh weight were monitored at $0.5 \mathrm{~h}, 1 \mathrm{~h}, 2 \mathrm{~h}, 3 \mathrm{~h}$, and $4 \mathrm{~h}$. Water loss is expressed as the percentage of initial fresh weight. All stress assays were performed three times.

\subsection{Expression Profile of Stress-Related Genes}

To elucidate the possible molecular mechanisms of $Z m W R K Y 40$, the expression levels of $S T Z$, $D R E B 2 B$, and RD29A were assessed in transgenic and WT plants under normal condition by qRT-PCR. The specific primers are listed in Supplementary Table S1.

\subsection{Measurements of Physiological-Biochemical Parameters}

The reactive oxygen species (ROS) content, and the activities of peroxide dismutase (POD) and catalase (CAT), were assessed in transgenic and WT plants at $0 \mathrm{~h}, 6 \mathrm{~h}$, and $24 \mathrm{~h}$ after drought treatment as previously described [60].

\section{Conclusions}

We identified a putative drought-responsive WRKY gene, ZmWRKY40, a member of group II, from the maize genome by de novo transcriptome sequencing (SRP144573). ZmWRKY40 protein was localized in the nucleus. ZmWRKY40 was induced by drought, high-temperature, $\mathrm{NaCl}$, and ABA treatments. Further research revealed that $Z m W R K Y 40$ could improve drought tolerance in transgenic Arabidopsis, and overexpression of ZmWRKY40 reduced ROS content and enhanced the activities of POD and CAT under drought treatment. Furthermore, ZmWRKY40 changed the expression of stress-responsive genes, including $S T Z, D R E B 2 B$, and $R D 29 A$. These results may provide a basis to understand the functions of $Z m W R K Y 40$ in drought resistance in maize. 
Supplementary Materials: Supplementary materials can be found at http:/ /www.mdpi.com/1422-0067/19/ 9/2580/s1. Supplementary Table S1. Primers used in the paper. Supplementary Table S2. The differentially expressed ZmWRKYs screened from maize de novo transcriptome sequencing under drought stress. Supplementary Figure S1. De novo transcriptome sequencing analysis of maize under drought stress. (A) The cluster analysis of DEGs under drought treatment. (B) The KEGG analysis of the DEGs between control and drought treatment. The left Y-axis indicated the KEGG pathway. The X-axis indicated the Rich factor. A high q-value was represented by blue, and a low q-value was represented by red. (C) The enrichments of Go terms for DEGs between control and drought treatment.

Author Contributions: Conceptualization, C.-T.W., J.-N.R., and J.-F.Y.; Methodology, C.-T.W., J.-N.R., and Y.-W.L.; Validation, C.-T.W., J.-N.R., and Y.-W.L.; Formal Analysis, C.-T.W. and J.-N.R.; Investigation, C.-T.W. and J.-N.R.; Data C.-T.W. and J.-N.R.; Writing-Original Draft Preparation, C.-T.W. and J.-N.R.; Writing-Review \& Editing, Z.-S.X. and J.-D.F.; Supervision, J.-F.Y. and Y.-W.L.; Project Administration, M.L.; Funding Acquisition, M.L.

Funding: This research was funded by the Funding Project for Beijing Advanced Innovation Center for Food Nutrition and Human Health, and the Open Research Fund Program of Beijing Key Lab of Plant Resource Research and Development, Beijing Technology and Business University.

Acknowledgments: We are very thankful to Li-Na Ning for critically reading the manuscript.

Conflicts of Interest: The authors declare no conflict of interest.

\section{Abbreviations}

$\begin{array}{ll}\text { ABA } & \text { abscisic acid } \\ \text { ABRE } & \text { ABA-responsive element } \\ \text { GA } & \text { gibberellin } \\ \text { GARE } & \text { GA-responsive element } \\ \text { GFP } & \text { green fluorescent protein } \\ \text { qRT-PCR } & \text { quantitative real-time PCR } \\ \text { RT-PCR } & \text { reverse transcription PCR } \\ \text { SA } & \text { salicylic acid } \\ \text { TF } & \text { transcription factor } \\ \text { WT } & \text { wild type }\end{array}$

\section{References}

1. Feng, Z.J.; Cui, X.Y.; Cui, X.Y.; Chen, M.; Yang, G.X.; Ma, Y.Z.; He, G.Y.; Xu, Z.S. The soybean GmDi19-5 interacts with GmLEA3.1 and increases sensitivity of transgenic plants to abiotic stresses. Front. Plant Sci. 2015, 6, 179. [CrossRef] [PubMed]

2. Li, P.S.; Yu, T.F.; He, G.H.; Chen, M.; Zhou, Y.B.; Chai, S.C.; Xu, Z.S.; Ma, Y.Z. Genome-wide analysis of the Hsf family in soybean and functional identification of GmHsf-34 involvement in drought and heat stresses. BMC Genom. 2014, 15, 1009. [CrossRef] [PubMed]

3. Xu, Z.S.; Chen, M.; Li, L.C.; Ma, Y.Z. Functions and application of the AP2/ERF transcription factor family in crop improvement. J. Integr. Plant Biol. 2011, 53, 570-585. [CrossRef] [PubMed]

4. Xu, Z.S.; Chen, M.; Li, L.C.; Ma, Y.Z. Functions of the ERF transcription factor family in plants. Botany 2008, 86, 969-977. [CrossRef]

5. Song, L.; Huang, S.C.; Wise, A.; Castanon, R.; Nery, J.R.; Chen, H.M.; Watanabe, M.; Thomas, J.; Joseph, Z.B.; Ecker, J.R. A transcription factor hierarchy defines an environmental stress response network. Science 2016, 354, 6312. [CrossRef] [PubMed]

6. Shani, E.; Salehin, M.; Zhang, Y.Q.; Sanchez, S.E.; Doherty, C.; Wang, R.H.; Mangado, C.C.; Song, L.; Tal, I.; Pisanty, O. Plant stress tolerance requires Auxin-sensitive Aux/IAA transcriptional repressors. Curr. Biol. 2017, 27, 437-444. [CrossRef] [PubMed]

7. Eulgem, T.; Rushton, P.J.; Robatzek, S.; Somssich, I.E. The WRKY superfamily of plant transcription factor. Trends Plant Sci. 2000, 5, 199-206. [CrossRef]

8. Ulker, B.; Somssich, I.E. WRKY transcription factors: From DNA binding towards biological function. Curr. Opin. Plant Biol. 2004, 7, 491-498. [CrossRef] [PubMed] 
9. Ishiguro, S.; Nakamura, K. Characterization of a cDNA encoding a novel DNA-binding protein, SPF1, that recognizes SP8 sequences in the $5^{\prime}$ upstream regions of genes coding for sporamin and $\beta$-amylase from sweet potato. Mol. Gen. Genet. 1994, 244, 563-571. [CrossRef] [PubMed]

10. Glöckner, G.; Eichinger, L.; Szafranski, K.; Pachebat, J.A.; Bankier, A.T.; Dear, P.H.; Lehmann, R.; Baumgart, C.; Parra, G.; Abril, J.F.; et al. Sequence and analysis of chromosome 2 of Dictyostelium discoideum. Nature 2002, 418, 79-85. [CrossRef] [PubMed]

11. Kim, C.Y.; Lee, S.H.; Park, H.C.; Bae, C.G.; Cheong, Y.H.; Choi, Y.J.; Han, C.; Lee, S.Y.; Lim, C.O.; Cho, M.J. Identification of rice blast fungal elicitor-responsive genes by differential display analysis. Mol. Plant Microbe Interact. 2000, 13, 470-474. [CrossRef] [PubMed]

12. Schmutz, J.; Cannon, S.B.; Schlueter, J.; Ma, J.; Mitros, T.; Nelson, W.; Hyten, D.L.; Song, Q.; Thelen, J.J.; Cheng, J.; et al. Genome sequence of the palaeopolyploid soybean. Nature 2010, 463, 178-183. [CrossRef] [PubMed]

13. Mangelsen, E.; Kilian, J.; Berendzen, K.W.; Kolukisaoglu, U.H.; Harter, K.; Jansson, C.; Wanke, D. Phylogenetic and comparative gene expression analysis of barley (Hordeum vulgare) WRKY transcription factor family reveals putatively retained functions between monocots and dicots. BMC Genom. 2008, 9, 194. [CrossRef] [PubMed]

14. Chen, J.N.; Nolan, T.M.; Ye, H.X.; Zhang, M.C.; Tong, H.N.; Xin, P.Y.; Chu, J.F.; Chu, C.C.; Li, Z.H.; Yin, Y.H. Arabidopsis WRKY46, WRKY54, and WRKY70 transcription factors are involved in brassinosteroid-regulated plant growth and drought responses. Plant Cell 2017, 29, 1425-1439. [CrossRef] [PubMed]

15. Jiang, J.J.; Ma, S.H.; Ye, N.H.; Jiang, M.; Cao, J.S.; Zhang, J.H. WRKY transcription factors in plant responses to stresses. J. Integr. Plant Biol. 2017, 59, 86-101. [CrossRef] [PubMed]

16. Li, S.J.; Fu, Q.T.; Chen, L.G.; Huang, W.D.; Yu, D.Q. Arabidopsis thaliana WRKY25, WRKY26, and WRKY33 coordinate induction of plant thermotolerance. Planta 2011, 233, 1237-1252. [CrossRef] [PubMed]

17. Li, S.J.; Zhou, X.; Chen, L.G.; Huang, W.D.; Yu, D.Q. Functional characterization of Arabidopsis thaliana WRKY39 in heat stress. Mol. Cells 2010, 29, 475-483. [CrossRef] [PubMed]

18. Dang, F.F.; Wang, Y.N.; Yu, L.; Eulgem, T.; Lai, Y.; Liu, Z.Q.; Wang, X.; Qiu, A.L.; Zhang, T.X.; Lin, J.; et al. CaWRKY40, a WRKY protein of pepper, plays an important role in the regulation of tolerance to heat stress and resistance to Ralstonia solanacearum infection. Plant Cell Environ. 2013, 36, 757-774. [CrossRef] [PubMed]

19. Zhou, Q.Y.; Tian, A.G.; Zou, H.F.; Xie, Z.M.; Lei, G.; Huang, J.; Wang, C.M.; Wang, H.W.; Zhang, J.S.; Chen, S.Y. Soybean WRKY-type transcription factor genes, GmWRKY13, GmWRKY21, and GmWRKY54, confer differential tolerance to abiotic stresses in transgenic Arabidopsis plants. Plant Biotechnol. J. 2008, 6, 486-503. [CrossRef] [PubMed]

20. He, G.H.; Xu, J.Y.; Wang, Y.X.; Liu, J.M.; Li, P.S.; Chen, M.; Ma, Y.Z.; Xu, Z.S. Drought-responsive WRKY transcription factor genes TaWRKY1 and TaWRKY33 from wheat confer drought and/or heat resistance in Arabidopsis. BMC Plant Biol. 2016, 16, 116. [CrossRef] [PubMed]

21. Shang, Y.; Yan, L.; Liu, Z.Q.; Cao, Z.; Mei, C.; Xin, Q.; Wu, F.Q.; Wang, X.F.; Du, S.Y.; Jiang, T. The Mg-chelatase $\mathrm{H}$ subunit of Arabidopsis antagonizes a group of WRKY transcription repressors to relieve ABA-responsive genes of inhibition. Plant Cell 2010, 22, 1909-1935. [CrossRef] [PubMed]

22. Zhao, W.; Liu, Y.W.; Zhou, J.M.; Zhao, S.P.; Zhang, X.H.; Min, D.H. Genome-wide analysis of the lectin receptor-like kinase family in foxtail millet (Setaria italica L.). Plant Cell Tissue Organ Cult. 2016, 127, 335-346. [CrossRef]

23. Wei, K.F.; Chen, J.; Chen, Y.F.; Wu, L.J.; Xie, D.X. Molecular phylogenetic and expression analysis of the complete WRKY transcription factor family in maize. DNA Res. 2012, 19, 153-164. [CrossRef] [PubMed]

24. Liu, J.M.; Zhao, J.Y.; Lu, P.P.; Chen, M.; Guo, C.H.; Xu, Z.S.; Ma, Y.Z. The E-Subgroup pentatricopeptide repeat protein family in Arabidopsis thaliana and confirmation of the responsiveness PPR96 to abiotic stresses. Front. Plant Sci. 2016, 7, 1825. [CrossRef] [PubMed]

25. Yu, T.F.; Xu, Z.S.; Guo, J.K.; Wang, Y.X.; Abernathy, B.; Fu, J.D.; Chen, X.; Zhou, Y.B.; Chen, M.; Ye, X.G.; et al. Improved drought tolerance in wheat plants overexpressing a synthetic bacterial cold shock protein gene SeCspA. Sci. Rep. 2017, 7, 44050. [CrossRef] [PubMed]

26. Journot-Catalino, N.; Somssich, I.E.; Roby, D.; Kroj, T. The transcription factors WRKY11 and WRKY17 act as negative regulators of basal resistance in Arabidopsis thaliana. Plant Cell 2006, 18, 3289-3302. [CrossRef] [PubMed] 
27. Niu, C.F.; Wei, W.; Zhou, Q.Y.; Tian, A.G.; Hao, Y.J.; Zhang, W.K.; Ma, B.; Lin, Q.; Zhang, Z.B.; Zhang, J.S.; et al. Wheat WRKY genes TaWRKY2 and TaWRKY19 regulate abiotic stress tolerance in transgenic Arabidopsis. Plant Cell Environ. 2012, 35, 1156-1170. [CrossRef] [PubMed]

28. Shi, W.; Hao, L.L.; Li, J.; Liu, D.D.; Guo, X.Q.; Li, H. The Gossypium hirsutum WRKY gene GhWRKY39-1 promotes pathogen infection defense responses and mediates salt stress tolerance in transgenic Nicotiana benthamiana. Plant Cell Rep. 2014, 33, 483-498. [CrossRef] [PubMed]

29. Dong, J.X.; Chen, C.H.; Chen, Z.X. Expression profiles of the Arabidopsis WRKY gene superfamily during plant defense response. Plant Mol. Biol. 2003, 51, 21-37. [CrossRef] [PubMed]

30. Hu, Y.R.; Dong, Q.Y.; Yu, D.Q. Arabidopsis WRKY46 coordinates with WRKY70 and WRKY53 in basal resistance against pathogen Pseudomonas syringae. Plant Sci. 2012, 288-297. [CrossRef] [PubMed]

31. Ryu, H.S.; Han, M.; Lee, S.K.; Cho, J.I.; Ryoo, N.; Heu, S.; Lee, Y.H.; Bhoo, S.H.; Wang, G.L.; Hahn, T.R.; et al. A comprehensive expression analysis of the WRKY gene superfamily in rice plants during defense response. Plant Cell Rep. 2006, 25, 836-847. [CrossRef] [PubMed]

32. Wang, C.; Deng, P.Y.; Chen, L.L.; Wang, X.T.; Ma, H.; Hu, W.; Yao, N.C.; Feng, Y.; Chai, R.H.; Yang, G.X.; et al. A Wheat WRKY transcription factor TaWRKY10 confers tolerance to multiple abiotic stresses in transgenic tobacco. PLoS ONE 2013, 8, e65120. [CrossRef] [PubMed]

33. Wang, F.; Hou, X.L.; Tang, J.; Wang, Z.; Wang, S.M.; Jiang, F.L.; Li, Y. A novel cold-inducible gene from Pak-choi (Brassica campestris ssp. chinensis), BcWRKY46, enhances the cold, salt and dehydration stress tolerance in transgenic tobacco. Mol. Biol. Rep. 2012, 39, 4553-4564. [CrossRef] [PubMed]

34. Scarpeci, T.E.; Zanor, M.I.; Mueller-Roeber, B.; Valle, E.M. Overexpression of AtWRKY30 enhances abiotic stress tolerance during early growth stages in Arabidopsis thaliana. Plant Mol. Biol. 2013, 83, 265-277. [CrossRef] [PubMed]

35. Jiang, Y.J.; Liang, G.; Yu, D.Q. Activated expression of WRKY57 confers drought tolerance in Arabidopsis. Mol. Plant 2012, 5, 1375-1388. [CrossRef] [PubMed]

36. Jiang, Y.J.; Qiu, Y.P.; Hu, Y.R.; Yu, D.Q. Heterologous expression of AtWRKY57 confers drought tolerance in Oryza sativa. Front. Plant Sci. 2016, 7, 145. [CrossRef] [PubMed]

37. Qiu, Y.P.; Yu, D.Q. Over-expression of the stress-induced OsWRKY45 enhances disease resistance and drought tolerance in Arabidopsis. Environ. Exp. Bot. 2009, 65, 35-47. [CrossRef]

38. Wu, H.L.; Ni, Z.F.; Yao, Y.Y.; Guo, G.G.; Sun, Q.X. Cloning and expression profiles of 15 genes encoding WRKY transcription factor in wheat (Triticum aestivem L.). Prog. Nat. Sci. 2008, 8, 697-705. [CrossRef]

39. Wang, F.; Chen, H.W.; Li, Q.T.; Wei, W.; Li, W.; Zhang, W.K.; Ma, B.; Bi, Y.D.; Lai, Y.C.; Liu, X.L. GmWRKY27 interacts with GmMYB174 to reduce expression of GmNAC29 for stress tolerance in soybean plants. Plant J. 2015, 83, 224-236. [CrossRef] [PubMed]

40. Li, H.; Gao, Y.; Xu, H.; Dai, Y.; Deng, D.Q.; Chen, J.M. ZmWRKY33, a WRKY maize transcription factor conferring enhanced salt stress tolerances in Arabidopsis. Plant Growth Regul. 2013, 70, 207-216. [CrossRef]

41. Liu, P.; Xu, Z.S.; Li, P.P.; Hu, D.; Chen, M.; Li, L.C.; Ma, Y.Z. A wheat PI4K gene whose product possesses threonine autophophorylation activity confers tolerance to drought and salt in Arabidopsis. J. Exp. Bot. 2013, 64, 2915-2927. [CrossRef] [PubMed]

42. Schnable, P.S.; Ware, D.; Fulton, R.S.; Stein, J.C.; Wei, F.; Pasternak, S.; Liang, C.; Zhang, J.; Fulton, L.; Graves, T.A.; et al. The B73 maize genome: Complexity, diversity, and dynamics. Science 2009, 326, 1112-1115. [CrossRef] [PubMed]

43. Cai, R.H.; Dai, W.; Zhang, C.S.; Wang, Y.; Wu, M.; Zhao, Y.; Ma, Q.; Xiang, Y.; Cheng, B.J. The maize WRKY transcription factor ZmWRKY17 negatively regulates salt stress tolerance in transgenic Arabidopsis plants. Planta 2017, 246, 1215-1231. [CrossRef] [PubMed]

44. Cai, R.H.; Zhao, Y.; Wang, Y.F.; Lin, Y.X.; Peng, X.J.; Li, Q.; Chang, Y.W.; Jiang, H.Y.; Xiang, Y.; Cheng, B.J. Overexpression of a maize WRKY58 gene enhances drought and salt tolerance in transgenic rice. Plant Cell Tissue Organ Cult. 2014, 119, 565-577. [CrossRef]

45. Jia, H.H.; Wang, C.; Wang, F.; Liu, S.C.; Li, G.L.; Guo, X.Q. GhWRKY68 reduces resistance to salt and drought in transgenic Nicotiana benthamiana. PLoS ONE 2015, 10, e0120646. [CrossRef] [PubMed]

46. Shinzaki, K.; Yamaguchi-Shinozaki, K. Gene networks involved in drought stress response and tolerance. J. Exp. Bot. 2007, 58, 221-227. [CrossRef] [PubMed]

47. Farooq, M.; Wahid, A.; Lee, D.J.; Ito, O.; Siddique, K.H.M. Advances in drought resistance of Rice. Crit. Rev. Plant Sci. 2009, 28, 199-217. [CrossRef] 
48. Wang, C.; Lu, G.; Hao, Y.; Guo, H.; Guo, Y.; Zhao, J.; Cheng, H. ABP9, a maize bZIP transcription factor, enhances tolerance to salt and drought in transgenic cotton. Planta 2017, 246, 453-469. [CrossRef] [PubMed]

49. Taheri, P.; Kakooee, T. Reactive oxygen species accumulation and homeostasis are involved in plant immunity to an opportunistic fungal pathogen. J. Plant Physiol. 2017, 216, 152-163. [CrossRef] [PubMed]

50. Fang, Y.; Liao, K.; Du, H.; Xu, Y.; Song, H.; Li, X.; Xiong, L. A stress-responsive NAC transcription factor SNAC3 confers heat and drought tolerance through modulation of reactive oxygen species in rice. J. Exp. Bot. 2015, 66, 6803-6817. [CrossRef] [PubMed]

51. Swain, D.M.; Sahoo, R.K.; Srivastava, V.K.; Tripathy, B.C.; Tuteja, R.; Tuteja, N. Function of heterotrimeric G-protein gamma subunit RGG1 in providing salinity stress tolerance in rice by elevating detoxifcation of ROS. Planta 2017, 245, 367-383. [CrossRef] [PubMed]

52. Mittler, R.; Kim, Y.S.; Song, L.H.; Coutu, J.; Coutu, A.; Ciftci-Yilmaz, S.; Lee, H.J.; Stevenson, B.; Zhu, J.K. Gain- and loss-of-function mutations in Zat10 enhance the tolerance of plants to abiotic stress. FEBS Lett. 2006, 580, 6537-6542. [CrossRef] [PubMed]

53. Sakuraba, Y.; Kim, Y.S.; Han, S.H.; Lee, B.D.; Paek, N.C. The Arabidopsis transcription factor NAC016 promotes drought stress responses by repressing $A R E B 1$ transcription through a trifurcate feed-forward regulatory loop involving NAP. Plant Cell 2015, 27, 1771-1787. [CrossRef] [PubMed]

54. Narusaka, Y.; Nakashima, K.; Shinwari, Z.K.; Sakuma, Y.; Furihata, T.; Abe, H.; Narusaka, M.; Shinozaki, K.; Yamaguchi-Shinozaki, K. Interaction between two cis-acting elements, ABRE and DRE, in ABA-dependent expression of Arabidopsis rd29A gene in response to dehydration and high-salinity stresses. Plant J. 2003, 34, 137-148. [CrossRef] [PubMed]

55. Song, W.B.; Zhao, H.M.; Zhang, X.B.; Lei, L.L.; Lai, J.S. Genome-Wide identification of VQ motif-containing proteins and their expression profiles under abiotic stresses in Maize. Front. Plant Sci. 2016, 6, 1177. [CrossRef] [PubMed]

56. Le, D.T.; Nishiyama, R.; Watanabe, Y.; Mochida, K.; Yamaguchi-Shinozaki, K.; Shinozaki, K.; Tran, L.S. Genome-Wide expression profiling of soybean two-component system genes in soybean root and shoot tissues under dehydration stress. DNA Res. 2011, 18, 17-29. [CrossRef] [PubMed]

57. Thompson, J.D.; Gibson, T.J.; Plewniak, F.; Jeanmougin, F.; Higgins, D.G. The CLUSTAL_X windows interface: Flexible strategies for multiple sequence alignment aided by quality analysis tools. Nucleic Acids Res. 1997, 25, 4876-4882. [CrossRef] [PubMed]

58. Tamura, K.; Peterson, D.; Peterson, N.; Stecher, G.; Nei, M.; Kumar, S. MEGA5: Molecular evolutionary genetics analysis using maximum likelihood, evolutionary distance, and maximum parsimony methods. Mol. Biol. Evol. 2011, 28, 2731-2739. [CrossRef] [PubMed]

59. Jiang, A.L.; Xu, Z.S.; Zhao, Z.Y.; Cui, X.Y.; Chen, M.; Li, L.C.; Ma, Y.Z. Genome-wide analysis of C3H zinc finger transcription factor family and their drought responses in Aegilops tauschii. PMB Rep. 2014, 32, 1241-1256. [CrossRef]

60. Jaffar, M.A.; Song, A.; Faheem, M.; Chen, S.; Jiang, J.; Liu, C.; Fan, Q.; Chen, F. Involvement of CmWRKY10 in drought tolerance of chrysanthemum through the ABA-Signaling pathway. Int. J. Mol. Sci. 2016, 17, 693. [CrossRef] [PubMed]

(C) 2018 by the authors. Licensee MDPI, Basel, Switzerland. This article is an open access article distributed under the terms and conditions of the Creative Commons Attribution (CC BY) license (http://creativecommons.org/licenses/by/4.0/). 